\title{
A influência das TICs na comunicação entre pesquisa e extensão rural: uma análise da Web como canal de informação técnico-científica para extensionistas
}

Pricila Estevão ${ }^{1}$

Diego Neves de Sousa ${ }^{2}$

\begin{abstract}
Resumo
Com a emergência da Tecnologias da Inovação e Comunicação (TICS), propõe-se analisar quais as potencialidades e limites dessas ferramentas tecnológicas como canal de divulgação de informações científicas, técnicas e tecnológicas e na comunicação entre pesquisa e extensão rural através da percepção de técnicos extensionistas. A pesquisa utilizou-se do método survey para o levantamento dos dados primários junto à extensionistas de duas importantes regiões mineiras na produção leiteira. Entre os resultados, verifica-se que, em geral, a Web como meio de comunicação e interação ainda não está apropriada pelos extensionistas. A utilização dos canais Web é baixa em comparação a outros canais de comunicação presenciais.
\end{abstract}

Palavras-chave: Tecnologias digitais; mediadores; desenvolvimento rural.

\section{The influence of ICTs in the communication between research and rural extension: an analysis of the Web as a channel of technical- scientific information for extension workers}

\begin{abstract}
With the emergence of TICs, we seek to analyze the potential and limits of these technological tools as a channel for the dissemination of scientific, technical and technological information and in the communication between research and rural extension through the perception of extension technicians. The research used the survey method to gather primary data from extension workers from two important regions of Minas Gerais State in milk production. Among the results, it appears that, in general, the Web as a means of communication and interaction is not yet appropriated by extension workers. The use of Web channels is low compared to other face-to-face communication channels.
\end{abstract}

Keywords: Digital technologies; mediators; rural development.

\section{Introdução}

As Tecnologias da Inovação e Comunicação (TICs) têm originado uma verdadeira revolução em diversas profissões e atividades, incluindo a investigação científica e a administração pública. Assim, as TICs contribuem "pelas várias potencialidades que trazem de criação de espaços de interação e comunicação, pelas possibilidades alternativas que fornecem de expressão criativa, de realização de projetos em conjunto e de reflexão crítica" (PONTE, 2000, p. 75).

1 Mestra em Extensão Rural. Relações Públicas da Embrapa Gado de Leite (Juiz de Fora-MG). pricila.estevao@embrapa.br

2 Doutor em Desenvolvimento Rural. Analista da Embrapa Pesca e Aquicultura (Palmas-TO). diegocoop@hotmail.com 
Com o surgimento da Internet, a influência que estas tecnologias exercem nas interações humanas foi particularmente acentuada. Segundo Ponte (2000), não se pode falar da sociedade da informação sem considerar a ligação em rede de computadores e redes, à escala global, possibilitando o acesso imediato a todo o tipo de informações e serviços.

O conceito de rede, no entanto, não é novo. Os seres humanos, como seres sociais, estão permanentemente envolvidos numa teia de relações que desempenham um papel estruturante nos campos cognitivo e social. O que assistimos, nos anos recentes, foi a um salto qualitativo, passando essas teias de relações a incluir as redes telemáticas que põem cada um de nós em contato com pessoas e entidades em qualquer lugar do planeta.

As redes não são mais do que estruturas que viabilizam a interação entre os seres humanos e, desse modo, a construção de significados. Por meio da comunicação, estas redes conduzem ao surgimento de comunidades e, desse modo, potencializam novas oportunidades de comunicação. As comunidades conduzem ao estabelecimento de valores nos quais se legitimam as redes intersubjetivas onde os seres humanos se inserem (BLUMER, 2000). Estas redes, para Silva (1999), enquanto redes de partilha, participação, associação e formação de identidades, são, por um lado, produtos e, por outro, produtoras da humanidade. Assim, redes intersubjetivas existem desde que existe humanidade, "mas o fenômeno que se afirma como específico dos finais do século XX é o fato de as redes terem vindo a sofrer um processo de dilatação e complexificação progressiva, que culmina na globalização das tecnologias da informática e das telecomunicações" (SILVA, 1999, p. 54).

Segundo Lévy (1997), as pessoas no ciberespaço não procuram só a informação, procuram também a relação, a afirmação e a pertença a grupos. Ou seja, a Internet tem fundamentalmente uma dimensão social. As tecnologias em rede propiciam a existência de ambientes intermediários entre sujeitos que permitem fundar comunidades reais, no sentido em que existe interatividade entre os indivíduos, mas também virtuais, na medida em que não existe presença física.

As comunidades virtuais são reais, na medida em que existem e fazem parte da vida das pessoas, porém não são comunidades físicas e não seguem os mesmos modelos de comunicação e interação dessas comunidades, mas são redes sociais interpessoais, em sua maioria baseada em laços fracos, sendo ao mesmo tempo, diversificadas e especializadas não se opondo às comunidades físicas (CASTELLS, 2003). Entretanto, parece que as comunidades virtuais "são mais fortes do que os observadores em geral acreditam. Existem indícios substanciais de solidariedade 
recíproca na Rede, mesmo entre usuários com laços fracos entre si. De fato, a comunicação online incentiva discussões desinibidas" (CASTELLS, 2003, p. 445),

Deste modo, não devemos ver o ciberespaço como apenas um repositório de informação. Mais do que isso, ele é um lugar propiciador da dinâmica social, em que a própria informação perde o seu caráter estático e adquire uma dinâmica de mudança constante, alterando-se, crescendo e permitindo aos seus criadores a sua apropriação de forma transformadora (PONTE, 2000).

Além disso, para o autor, os "usuários" da Internet não podem ser considerados somente consumidores e produtores de informação, são ainda seres eminentemente sociais que, ao usar a Internet, procuram pertencer a um ou mais grupos e afirmar as suas convicções políticas, culturais, profissionais, e também procuram ajuda para ultrapassar as suas dificuldades pessoais ou coletivas.

A Internet, com os seus mecanismos de comunicação, revelou-se um catalisador e mesmo um instrumento insuperável para a cooperação entre pessoas e grupos que trabalham em um objetivo comum, bem definido, a ponto de surpreender até mesmo os maiores especialistas da área. Existem inúmeros exemplos deste fenômeno, mas talvez o caso mais dramático seja aquele do desenvolvimento cooperativo do sistema operacional Linux (SIMON, 1997).

Assim sendo, pode-se dizer que as relações de cooperação são imprescindíveis para a constituição de novos conhecimentos e saberes. E a Web, em princípio, teria esse potencial ao acentuar a necessidade de processos de construção compartilhada de conhecimentos e aproximando grupos distintos e distantes, mas com objetivos comuns.

Não obstante é preciso refletir que a Web não acontece fora das contradições sociais do mundo físico. Ela é uma forma diferente e nova de reprodução social, pois em um ambiente virtual não desaparecem as desigualdades sociais e de poder. Por isso, dependendo da forma como a Web é apresentada e utilizada pelas fontes de informação pode ser tanto um meio de alienação quanto de empoderamento e liberdade. Para este estudo, conforme o recorte epistemológico interessa analisar quais as potencialidades e limites das ferramentas tecnológicas como canal de divulgação de informações científicas, técnicas e tecnológicas e na comunicação entre pesquisa e extensão rural através da percepção de técnicos extensionistas.

Nos procedimentos metodológicos, este estudo utilizou o método survey para o levantamento dos dados primários. A coleta de dados foi feita por meio de questionários estruturados aplicados em entrevistas presenciais com extensionistas rurais de 20 municípios do estado de Minas Gerais, de duas expressivas mesorregiões na produção leiteira: a Zona da Mata 
Mineira, tradicional na produção e onde se localizam vários centros de ensino e pesquisa, inclusive a Embrapa Gado de Leite e o Triângulo Mineiro e Alto do Paranaíba, atualmente a mesorregião com maior produção de leite estadual. Dessas, foram selecionados os municípios polos: Cataguases e Uberaba, para representar respectivamente essas mesorregiões. Essas foram escolhidas intencionalmente por representarem regiões importantes e singulares da produção de leite no Estado e nacionalmente. Assim, a população da pesquisa foi composta por 73 agentes de Ater, provenientes de empresa pública e cooperativa.

\section{Potencialidades e limites da Web}

Como visto, a Web representa, além do acesso à informação, de produção e divulgação de conteúdos próprios, possibilidades de interação e construção de conhecimento em rede. A Internet é extremamente elástica e sua aceitação e disseminação está vinculada ao desenvolvimento do recurso World Wide Web, também conhecida como WWW, Web ou W3, a qual potencializou muito a Internet.

Apesar de comumente os termos Internet e Web serem usados como sinônimo, elas não são a mesma coisa. A Web é a interface gráfica da Internet. Nela os documentos estão apresentados em formas variadas como vídeos, sons, imagens e hipertextos. Para visualizar a informação, usa-se um navegador para descarregar informações, chamadas 'documentos' ou 'páginas', de servidores Web e mostrá-los na tela do usuário. A Web consiste de sites (localidades) acessíveis por provedores de acesso à Internet. Trata-se da versão ilustrada da Internet. Ela é, provavelmente, o primeiro passo efetivo na consolidação de uma rede de informações multimídia baseada em hipertextos integrando todo o planeta. Hoje, a Web é a forma padrão de acesso à Internet e principal responsável pela sua popularização e facilidade de utilização.

Com relação a outros meios de comunicação, Hofmann (apud LIMA, 2005) acredita que o potencial da Web seja maior que o da televisão, pois nela o espectador é ativo, procurando a informação desejada e podendo difundir suas opiniões. No entanto, em se tratando de recepção, a Web ainda é mais dispendiosa que outros meios, como a TV e o rádio, pois exige do sujeito a compra do aparato eletrônico e técnico para o acesso: computador, modem e provedor. Além disso, no caso da TV e do rádio não é necessário que a pessoa seja alfabetizada para utilizá-los, sendo requisito básico para o acesso da Internet e Web. Outro ponto ainda seria a questão do analfabetismo digital, ou seja, não saber utilizar de forma satisfatória os recursos proporcionados 
pela ferramenta tecnológica. Do ponto de vista técnico, ela trouxe enormes possibilidades, mas ainda se encontra em desenvolvimento, o que requer conhecer melhor as suas potencialidades e limites.

Ao se pensar na Web como espaço de comunicação e informação, aparecem as diferentes características marcantes desse novo meio, tais como: a interatividade, hipertextualidade e transversalidade, digitalização, multimídia, compartilhamento de canal, cooperação, informação distribuída, normatização e sistemas abertos, velocidade e instantaneidade. Dentre as potencialidades da Internet apresentadas acima, faz-se necessário aprofundar em algumas de suas características, como a hipertextualidade, a hipermídia e a interatividade, por sua aproximação ao objeto de estudo desta pesquisa, bem como por aspectos que dizem respeito ao seu poder de comunicação.

A primeira potencialidade da Web está na hipertextualidade. Ela não é um mero produto da tecnologia, mas um modelo relacionado com as formas de produzir e de organizar o conhecimento, que substitui sistemas conceituais fundados nas ideias de margem, hierarquia, linearidade, por outros de multilinearidade, nós, links e redes (LANDOW; DELANY, 1991). As redes digitais desterritorializaram o texto ao emergir um texto que não tem fronteiras rígidas e não há mais um 'texto', mas 'texto em movimento', em contínua mudança (LÉVY, 1997).

Com o avanço da informática e o desenvolvimento da Internet, e principalmente da Web, o hipertexto foi colocado em prática e tornou-se a técnica atual de armazenamento e apresentação da informação digital. Este estilo de texto é usado praticamente em todos os sites disponíveis na Internet, fornecendo uma maneira de se explorar grandes conteúdos textuais em espaços (telas) reduzidos. O hipertexto pode ser visto como um dos maiores recursos das mídias interativas, uma vez que a grande maioria das visitas aos sites existentes na Internet tem como objetivo a busca da informação. Essa informação, muitas vezes de grande extensão, só pode estar presente na Internet por meio do hipertexto, que a descentraliza em diversos fragmentos de textos menores interligados por links eletrônicos, o famoso "clique aqui para saber mais" (BARBOSA, 2004).

O hipertexto, segundo Lévy (1997), é o texto virtualizado, transformado em problemática textual pelo ser humano. Um ato de leitura é sempre um ato de criação. De acordo com o autor, a hipertextualização multiplica as ocasiões de produção do sentido e enriquece a leitura. A riqueza a que Lévy se refere é a potencialidade que o suporte digital disponibiliza de permitir novos tipos de leitura e de escrita coletiva. Tal suporte comporta um continuum variado que se estende entre a leitura individual de um texto preciso e a navegação em vastas redes digitais nas 
quais muitas pessoas anota, aumenta, conecta os textos uns aos outros por meio da hipertextualização. A leitura hipertextual, portanto, multiplica as ocasiões de produção de sentido e permite enriquecer consideravelmente a leitura.

O homem sempre desenvolveu, desde os primórdios da comunicação, maneiras de armazenar (para posteriormente recuperar) ideias, pensamentos e estórias das comunidades e grupos dos quais fazia parte. Esta habilidade vem crescendo de maneira surpreendente e inovadora desde o desenvolvimento das tecnologias digitais e da informática.

Nessa perspectiva tem-se mais uma das potencialidades da Web: a tecnologia multimídia. Responsável por condensar diversas formas representativas e linguagens numa única interface, apresentando vantagens na representação de um conjunto de informações que se interrelacionam, compondo um sistema. A linguagem multimídia que, como o próprio nome sugere, emprega recursos de todas as mídias. É uma linguagem eletrônica que une diferentes linguagens de arte e comunicação - texto, imagem, som, animação, vídeo - e com a qual o usuário pode interagir.

A componente multimídia desempenha um papel importante nos processos de comunicação e foi analisada e pormenorizada por Bidarra (1994). O autor identifica os vários códigos e linguagens que são aplicados. Os mais comuns são a linguagem falada; a linguagem escrita, gráfica ou infográfica, videográfica ou cinematográfica, não verbal e corporal, a representação cênica, a animação, a música e os efeitos sonoros.

Atualmente o conceito de audiovisual (proveniente das Ciências da Comunicação) fundese com o conceito de multimídia (ligado às Ciências da Informação), ambos dando origem à definição de uma tecnologia de base informática, sustentada por quatro linguagens digitais: audiográfica, videográfica, criptográfica (textos, gráficos, fotografias) e infográfica (imagens de síntese e animação). Ao serem estruturadas num hipertexto, são designadas de discurso hipermídia, estas linguagens constituem já uma outra entidade com características próprias, podendo ser tecnicamente formatadas para um suporte digital off line ( $C D-R O M, D V D-R O M)$ ou on-line (Web, TV interativa).

Hipermídia é a união do conceito de hipertexto com o de multimídia aqui apresentados. Não se caracteriza pela justaposição do texto escrito, da imagem fixa e em movimento e do áudio, mas de outra forma de percepção constituída pela combinação de todas ao mesmo tempo. Há um reposicionamento destas sublinguagens dentro da macrolinguagem multimídia e, por isto, elas assumem características distintas. 
Além disto, a linguagem hipermídia ocorre em um suporte tecnológico midiático que se caracteriza pela interatividade e constituição de relacionamentos em redes. Os conceitos de produtor e consumidor e de tempos de produção e consumo da informação são flexibilizados neste suporte midiático. Estas características distintas nos processos comunicativos estavam segmentadas em cada tipo de mídia (jornal impresso, televisão, rádio) e agora acontecem simultaneamente na Web.

O substrato ideal para desenvolver sistemas de interação hipermídia, de acordo com os modelos conceituais referidos, é, sem dúvida, a Web. A Web desafia o utilizador a envolver-se ativamente nos processos, permite experimentar diversos percursos, obriga a distinguir o que é importante do que é secundário, convida a criar e sintetizar material com base em várias fontes e estimula a formulação de questões novas. Contudo, não basta fornecer ao utilizador de páginas cheias de imagens animadas e sons. Torna-se necessário recorrer a um modelo que possa assegurar a eficácia dos processos cognitivos e simultaneamente proporcionar uma grande satisfação ao usuário ou interagente.

Assegurar a clareza e o impacto da comunicação é importante sempre que se aplicam códigos verbais, icônicos ou sonoros, assim torna-se primordial uma articulação eficaz entre a palavra e a imagem. Em primeiro lugar, a palavra escrita. Porém, importa lembrar que, apesar de existirem vantagens associadas à forma e à estética da escrita (fonte, cor, dimensão, etc.), esta é bem diferente da comunicação face a face, pois não transmite informação suplementar importante como a expressão facial, a mímica ou certos traços específicos da fala - entoação, acentuação, intensidade, pausas, silêncios, repetições, hesitações, etc. (BIDARRA, 1994).

O ser humano dispõe de cinco canais formais de comunicação, os quais correspondem aos seus cinco sentidos: audição, visão, tato, paladar e fala. Embora isto possa parecer óbvio, em geral nos esquecemos disso e, assim, deixamos de explorar as imensas possibilidades que isso representa na hora de elaborarmos e externarmos as nossas mensagens, principalmente pelo advento de novas tecnologias na área de informação e comunicação (SANTOS, 2005).

Na era da comunicação e do conhecimento, a imagem serve a propósitos que derivam do aparecimento de uma nova sociedade, interligada em rede, em interação constante, rápida nas decisões, globalmente informada e baseada na integração dos vários meios. Podemos afirmar, então, que existe uma necessidade de comunicar algo (áudio) visualmente, com uma boa relação custo-benefício. Esta perspectiva é sustentada pela interatividade dos sistemas multimídia e pela criatividade individual, sem muitas dificuldades de ordem técnica. Isto significa um aumento na capacidade de criar e de distribuir vídeo com relativa facilidade, passando a constituir um valor 
a mais à comunicação. Estamos diante de uma tendência global para ambientes interativos ricos em componentes audiovisuais.

A terceira e última potencialidade relacionada à Web é a interatividade ou interação mediada por computador, como muitos autores preferem denominar. Assim, antes de apresentar os conceitos de interatividade, considerada a maior potencialidade de comunicação da Web, é preciso conhecer melhor o que vem a ser a interação, pois é deste último conceito que deriva o primeiro: a interatividade.

A interação é uma "ação entre" os participantes do encontro (PRIMO, 1998), o foco se volta para a relação estabelecida entre os interagentes, e não nas partes que compõem o sistema global. Para Primo (2005, p. 2),

\begin{abstract}
o termo "usuário", tão utilizado nos estudos da "interatividade", deixa subentendido que tal figura está à mercê de alguém hierarquicamente superior, que coloca um pacote a sua disposição para uso (segundo as regras que determina). Preferirá adotar o termo "interagente" (uma tradução livre de interactant, não raro utilizado em pesquisas de comunicação interpessoal), que emana a própria ideia de interação.
\end{abstract}

Trivinho (1996, p.76), por sua vez, propõe o conceito de "indivíduo teleinteragente cyberspatial", que, segundo ele, "pressupõe um traço participativo-interventor cuja plenitude jamais foi verificada, por exemplo, num receptor da comunicação de massa. Nesse sentido, dizer 'receptor' parece realmente pouco". Portanto, neste trabalho prefere-se optar pelo termo interagente e pelo abandono de usuário e receptor.

Como visto, a interação varia qualitativamente de acordo com a relação mantida entre os envolvidos, indo progressivamente da interação mais reativa (programada e determinística) à de maior envolvimento e reciprocidade, a interação mútua (PRIMO, 2006). Autores como Lévy (1999), Lemos (2004) e Primo (2005) estabelecem níveis e divisões no processo de interação, processo este que no caso de humanos e máquinas é chamado de interatividade.

Interação e interatividade são conceitos para o qual não há consenso entre os estudiosos da área. Para alguns, o termo interatividade está associado às tecnologias, especialmente no que diz respeito às telecomunicações. Para Lemos (2004), a noção de interatividade está diretamente relacionada aos novos meios de comunicação digitais. O que se compreende hoje por interatividade nada mais é que uma forma de interação técnica, de cunho eletrônico-digital, diferente da interação analógica que caracterizou os meios de comunicação tradicionais. A interação homem-tecnologia é uma atividade tecnossocial presente em todas as etapas da civilização. Das tecnologias mais simples e rudimentares às mais complexas, como é o caso da Internet e da Web. Dessa forma, a 'interatividade' continua sendo "um dos conceitos mais 
centrais e um dos mais notoriamente difíceis de definir em pesquisa sobre meios de comunicação computacionais em geral, e em estudos de comunicação via Web em particular" (KLAUS JENSEN, 1998, p.3).

Diferentes tecnologias proporcionam diferenciados níveis de interatividade, o que irá depender diretamente da interface presente na tecnologia. Interface conforme defini Lévy (1999, p. 37) "são todos os aparatos materiais que permitem a interação entre o universo da informação digital e o mundo ordinário". Quando se fala em interação social mediada por computadores interligados em rede, podemos diferenciar a interação quanto a sua temporalidade, em síncrona e assíncrona, conforme ilustrado a seguir:

Interação síncrona: ocorre no mesmo tempo, ou seja, os sujeitos estão simultaneamente conectados, podendo acontecer no mesmo espaço ou em espaços diferentes. Interação assíncrona: ocorre em tempos e espaços diferentes, ou seja, os sujeitos não necessitam estar simultaneamente conectados ou no mesmo espaço para que a interação aconteça (MAÇADA; TIJIBOY, 1998, p.3).

Tanto a interação síncrona (em tempo real, on-line, como chats) como a assíncrona (off line, como os e-mails) podem variar quanto ao direcionamento e o número de sujeitos em interação. A interação pode ocorrer de "um para um" (possibilitada pelo telefone, e-mail, comunicadores instantâneos, dentre outros), de "um para muitos" (possibilitada principalmente pelos meios de comunicação de massa onde uma mesma mensagem é enviada para todos a partir de um centro de distribuição, como, por exemplo, na TV ou no Rádio, pode ainda acontecer num chat, e-mail, fórum, dentre outros), de "muitos para muitos", possibilitada em videoconferências, blogs, redes sociais, dentre outros (MAÇADA; TIJIBOY, 1998).

De opinião divergente temos autores como Rafaeli (1988) argumenta que os meios de comunicação são potenciais para que níveis de interatividade ganhem forma, embora não sejam suficientes para que isso ocorra. As definições e reflexões de Lemos (2004) sobre a interatividade estão ligadas ao conceito de interatividade reativa, apresentado por Primo $(1998,2005)$ e que está baseada no processo de estímulo-resposta e na abordagem informacional e tecnicista da comunicação.

Interagir é agir mutuamente. Porém, muito do que tem classificado como interativo é na verdade apenas reativo. "Reduzir a interação a aspectos meramente tecnológicos, em qualquer situação interativa, é desprezar a complexidade do processo de interação mediada. É fechar os olhos para o que há além do computador. Seria como tentar jogar futebol olhando apenas para a bola" (PRIMO, 2006, p.2). 
Na percepção de Primo (2005, p. 3), "é preciso observar os enfoques mais comuns da chamada 'interatividade' e ver se realmente valorizam a ação recíproca e a interdependência". De fato, as redes informáticas vieram transformar e ampliar as formas de comunicação à distância. Entretanto, trabalhar-se (tanto em pesquisa, quanto em desenvolvimento) a "interatividade" como uma polarização entre Webdesigner e "usuário" é manter-se preso à abordagem transmissionista de comunicação.

Não obstante, uma nova abordagem é proposta em que "a interação não deve ser vista como uma característica do meio, mas como um processo desenvolvido entre os interagentes" (PRIMO, 2005, p. 8). É uma abordagem sistêmico-relacional, chamada de interatividade mútua. Foi o autor quem apresentou este conceito baseado em estudos sobre interação e interação mediada pelo computador, como prefere chamar a interatividade. Importa investigar o que se passa "entre os sujeitos, entre o interagente humano e o computador, entre duas ou mais máquinas (...) que enfatiza o aspecto relacional da interação e busca valorizar a complexidade do sistema interativo" (PRIMO, 2005, p.10 e 11). Assim, para este autor,

na interação mútua, os interagentes reúnem-se em torno de contínuas problematizações. As soluções inventadas são apenas momentâneas, podendo participar de futuras problematizações. A própria relação entre os interagentes é um problema que motiva uma constante negociação. Cada ação expressa tem um impacto recursivo sobre a relação e sobre o comportamento dos interagentes. Isto é, o relacionamento entre os participantes vai definindo-se ao mesmo tempo que acontecem os eventos interativos (nunca isentos dos impactos contextuais). Devido a essa dinâmica, e em virtude dos sucessivos desequilíbrios que impulsionam a transformação do sistema, a interação mútua é um constante vir a ser, que se atualiza através das ações de um interagente em relação à(s) do(s) outro(s). Ou seja, a interação não é mera somatória de ações individuais (PRIMO, 2005, p.13).

A interação mútua, portanto, deve ser compreendida em contraste com a interação reativa (fraca e limitada). A palavra "mútua" foi escolhida pelo autor para salientar as modificações recíprocas dos interagentes durante o processo. Ao interagirem, um modifica o outro. Cada comportamento na interação é construído em virtude de ações anteriores. A construção do relacionamento, no entanto, não pode jamais ser previsível. Por conseguinte, o relacionamento construído entre eles também influencia recursivamente o comportamento de ambos. Dessa forma, justifica-se a escolha do termo "mútua", visando salientar o enlace dos interagentes e o impacto que cada comportamento oferece ao interagente, ao outro e à relação. Enquanto a interação mútua se desenvolve em virtude da negociação relacional, a interação reativa depende da previsibilidade e da automatização nas trocas (PRIMO, 2005). 
Do ponto de vista da comunicação, tecnologias como Facebook, Whatsapp, e-mail, fórum, lista de discussão e chat vieram facilitar o livre debate e a cooperação, apesar da distância geográfica entre os partícipes. Entretanto, "os arautos da interatividade não se cansam de celebrar as linguagens de programação e os sites ditos dinâmicos que automaticamente preenchem as páginas com informações fornecidas por um banco de dados" (PRIMO, 2006, p.4). Dessa forma, os conceitos apresentados pelo autor, no que se refere à interatividade em diferentes níveis de interação, podem dar um direcionamento melhor para o presente estudo. Pois apresentam características e discutem aspectos relevantes tanto da relação sujeito-sujeito quanto sujeito-máquina.

No que se refere às limitações da Web como veículo de comunicação e informação, as mais relevantes são as relacionadas à segurança, credibilidade de conteúdo, acesso restrito, reprodução de formatos e democratização limitada (ESTEVÃO, PINHO, SOUSA, 2016). Com relação à segurança e confiança de conteúdo, a Web enfrenta o descrédito e a desconfiança por parte de seus usuários, pelo fato de propagar constantemente muitos rumores e boatos eletrônicos, conhecidos como fake news. Além disso, sofre com a falta de credibilidade por concentrar uma grande quantidade de informações e por permitir que qualquer pessoa com acesso à Internet possa escrever e publicar os conteúdos que desejar (TERRA, 2006).

Comumente, nem todos os potenciais da Web são explorados, o que a iguala a formatos comunicacionais verticalizados e mediados por filtros editoriais diversos (ALAIC, 2005). Ainda, ela se depara com a força e a tradição dos demais veículos de comunicação de massa como a televisão, o rádio, os jornais e revistas impressos, já consolidadas (TERRA, 2006).

Numa visão crítica, a Web dá uma falsa ideia de democratização, uma vez que os usuários vão em busca daquilo que interessa, não se preocupando com opiniões discordantes. Elimina-se o confronto, o aprendizado. Corre-se o risco de fortalecer preconceitos e hábitos e o encorajamento da polarização e alienação (RADFAHRER, 2006). A Web ainda possui acesso limitado a uma pequena fatia privilegiada da população, aquela com poder aquisitivo maior e com maior instrução, o que desencadeia um processo de exclusão digital que reflete no social, aumentando as desigualdades.

Cada meio de comunicação possui sua própria linguagem, e a Web, enquanto novo meio tem também a sua. Com isso, o conteúdo informacional produzido especificamente para a Web tem que levar em conta suas especificidades e características peculiares, como visto até agora neste artigo. Outro cuidado é com a chamada arquitetura da informação, que consiste na tarefa de estruturar e distribuir as áreas principais e secundárias, tornando as informações facilmente 
identificáveis, sua distribuição bem definida e a navegação intuitiva (RODRIGUES, 2016). Também a usabilidade interfere nesse processo de comunicação de informações via Web.

\section{A Web como canal de informação técnico-científica: resultados e discussão}

Em um primeiro momento, buscou entender de forma mais aprofundada como a Web está sendo apropriada pelos extensionistas de duas microrregiões do estado de Minas Gerais estudadas, como canal de informação técnica na prática profissional de técnicos da extensão rural. Além disso, procurou saber a preferência deste público por outros canais de comunicação e informação convencionais em comparação aos trazidos pela Internet e Web.

As informações e análises serão apresentadas nesta seção, tentando traçar um perfil sobre a preferência por canais Web de divulgação técnico-científica e que estão sendo incorporados pelos extensionistas. De modo geral, verifica-se que as TICs têm desencadeado novas oportunidades para os mediadores sociais a partir da interação social, comunicacional e econômica, na qual potencializa vínculos que viabilizam a cooperação entre os próprios agricultores, ao estabelecerem laços comunicativos capazes de expandir o acesso a novos processos produtivos, tecnologias, mercados e redes de contatos (CONCEIÇÃO, 2016).

No que se refere ao acesso a canais de informação via Web, observa-se a preferência pelos técnicos de fontes externas à instituição que trabalha, como apontou $66 \%$ dos respondentes. Ao se comparar as microrregiões, percebe-se um percentual maior em Uberaba (73\%) do que em Cataguases (57\%).

Em se considerando a idade, $86 \%$ dos técnicos com idade inferior a 40 anos acessam fontes externas e $67 \%$ com mais de 51 anos preferem as fontes internas. Isso reflete uma tendência na qual os mais antigos de empresa confiam ou têm maior familiaridade e mais contato com canais Web da própria instituição, o que facilita encontrar as informações desejadas. Ademais, isso pode ser analisado do ponto de vista do conhecimento da Web, na qual os canais externos são em maior número, o que torna a busca mais complicada, demandando o domínio de outros aparatos tecnológicos e mais horas de navegação e dedicação para conhecer. Os motivos dessa preferência estão listados no Quadro 1.

A pesquisa mostrou que os entrevistados têm o hábito de acessar informações pela Web, dentre as mais acessadas estão as de natureza técnica (100\%), informações de mercado (55\%), legislação (34\%) e notícias (24\%). O que chama a atenção neste caso é a pouca preferência por informações ligadas a programas e editais de agricultura (indicada por apenas 7\% dos técnicos), 
por serem importantes fontes de financiamento de atividades de extensão e pesquisa. Talvez isso seja reflexo das poucas horas de acesso à Internet e pelo tempo gasto com a elaboração de relatórios, serviços burocráticos internos e orientação técnica individual, deixando em segundo plano a prospecção de projetos via edital, que demanda leitura e dedicação de tempo. Ou ainda por não existir a cultura da extensão rural em elaborar projetos, como apontou Estevão, Pinho e Sousa (2016).

Quadro 1 - Razões da preferência por fontes de informação internas e externas na Web na opinião dos extensionistas entrevistados

\begin{tabular}{|l|l|}
\hline Preferência por fontes internas & Preferência por fontes externas \\
\hline - Necessidade profissional e demanda & - As fontes externas são mais ricas em conteúdos \\
institucional (acessar normas, comunicados & técnicos necessários ao trabalho extensionista. \\
internos) e acessar material técnico, informações & - Pela disponibilidade de informações técnicas \\
úteis (técnicas) ao trabalho no dia a dia. & que outras instituições divulgam (quantidade e \\
- A informação é mais fácil (compreensão), pois & qualidade). \\
aquelas do site da Emater já foram filtradas e & - A empresa (LAC) não disponibiliza informações \\
transformadas em linguagens mais simples. & técnicas pela Web. \\
- Resposta mais rápida a dúvidas, confia nas & - O conteúdo disponibilizado pela Emater é muito \\
informações da Emater. & restrito e, às vezes, é desatualizado, assim é \\
- Maior facilidade de busca das informações, pois & preciso buscar material mais atualizado em \\
consideram que a Emater disponibiliza & fontes externas. \\
informações adequadas. & - Alguns trabalham com muitas atividades \\
- A Emater disponibiliza informações técnicas aos & diferentes que demandam informações de \\
extensionistas via portal técnico (tipo SAC). & diversas e diferentes fontes que não só da \\
- Por ter maior familiaridade com os canais Web & empresa e que internamente não encontram. \\
da sua empresa. & - A demanda é mais por pesquisa e tecnologia, o \\
- O acesso é somente para execução de trabalhos & que não é o foco da Emater. \\
internos. & - Para poderem ter informações mais \\
- A Emater tem muitos conteúdos técnicos & diversificadas sobre algum tema, ou seja, visões \\
interessantes, mas necessita de procurar & diferentes de um assunto. \\
informações externas para confrontar ideias e & - Necessitam de uma variedade de conteúdos \\
informações. & para aprofundar a intervenção sociotécnica. \\
\hline
\end{tabular}

Fonte: Dados da pesquisa.

Na comparação com as microrregiões, destaca-se a preferência por informações de mercado agrícola com quase o triplo das indicações em Uberaba (80\%) em relação a Cataguases (28\%). Em Cataguases o destaque é para as informações sobre legislação (50\%), sendo em Uberaba $20 \%$. Os assuntos preferidos pelos técnicos de cooperativas são as informações de mercado (67\%) e notícias em geral (22\%). O interesse por legislação em Cataguases pode ser explicado pelas características topográficas da região (relevo bastante acidentado), necessitando de um conhecimento maior sobre as novas leis ambientais, as quais afetam as propriedades da região e os técnicos estão sendo demandados por este assunto, conforme relatos feitos em entrevista. 
A obtenção das informações técnicas é feita por 93\% dos técnicos em sites de instituições públicas de pesquisa, como a Embrapa (93\%) e a Epamig (28\%). A Embrapa foi citada principalmente pela Unidade Gado de Leite (83\%), seguida da Unidade Mandioca e Fruticultura (38\%) e das Unidades Hortaliças e Milho e Sorgo (31\% cada uma). Este dado é reflexo da demanda dos produtores que, na maior parte, são de leite. As outras culturas agrícolas também refletem a demanda dos municípios estudados.

Os ministérios foram o segundo mais lembrado, com $48 \%$, porém mais utilizado para obtenção de informações sobre legislação em geral, por conter órgãos que regulam a maioria das atividades agropecuárias. Dentre os citados estão o extinto Ministério do Desenvolvimento Agrário - MDA (31\%), o Ministério da Agricultura, Pecuária e Abastecimento - Mapa (24\%) e Ministério do Desenvolvimento Social - MDS (3\%). Esta preferência está ligada à atividade principal desenvolvida, a agropecuária. E a maior lembrança do MDA é justificada pelo fato de ser este ministério que regulava até então as atividades de Assistência Técnica e Extensão Rural (Ater) no país. Já o Mapa controla a legislação sanitária e de produção relacionada à agricultura e pecuária brasileira (Tabela 1).

Tabela 1 - Sites visitados pelos técnicos para busca de informações

\begin{tabular}{|c|c|c|c|}
\hline \multirow[b]{2}{*}{ Tipo de site de Web } & \multicolumn{2}{|c|}{ Região } & \multirow{2}{*}{$\begin{array}{c}\text { Total geral } \\
(\%)\end{array}$} \\
\hline & $\begin{array}{c}\text { Cataguases } \\
(\%)\end{array}$ & $\begin{array}{c}\text { Uberaba } \\
(\%)\end{array}$ & \\
\hline Instituições públicas de pesquisa & 92 & 93 & 93 \\
\hline Ministérios & 64 & 33 & 48 \\
\hline Sites especializados em agropecuária & 36 & 53 & 45 \\
\hline Instituições públicas de Ater & 43 & 20 & 31 \\
\hline Universidades públicas & 14 & 33 & 24 \\
\hline Sites de busca & 21 & 27 & 24 \\
\hline $\begin{array}{l}\text { Secretárias e institutos estaduais } \\
\text { ligados à agricultura }\end{array}$ & 43 & 7 & 24 \\
\hline Sites de Notícias em geral & 21 & 7 & 17 \\
\hline Outras instituições e sites & 21 & 20 & 17 \\
\hline Total & $\mathrm{RM}(*)$ & $\mathrm{RM}\left({ }^{*}\right)$ & $\mathrm{RM}(*)$ \\
\hline Base $(*)$ & 14 & 15 & 29 \\
\hline
\end{tabular}

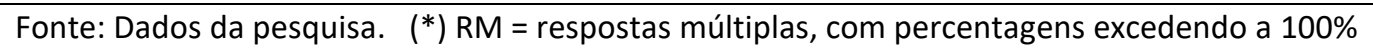
$(* *)$ Base $=$ número de respondentes

Dentre os sites especializados em agricultura e pecuária, os mais lembrados foram o Milkpoint (21\%), seguido do Cileite e do Globo Rural (10\% cada um). Os dois primeiros sites mostram a preferência pela busca por informações sobre o leite e específicas de mercado que são as especialidades deles. O Globo Rural foi citado, pois os técnicos disseram acessar, 
principalmente, para assistir as reportagens em vídeo que já foram ao ar na televisão e que ficam disponíveis no site do programa.

O site da Emater-MG foi citado por 33\% dos técnicos, todos funcionários da instituição. Também foram lembrados os sites da Emater do Rio Grande do Sul e da Coordenadoria de Assistência Técnica Integral - Cati, do Estado de São Paulo (3\% de indicação cada uma).

O que chama a atenção para estes dados sobre acesso a páginas na Web é sobre os sites de busca. Eles são utilizados por $24 \%$ dos técnicos a fim de encontrarem informações, através da pesquisa de palavras chaves. Apesar do uso aparentemente pequeno, ele pode ser arriscado, já que pesquisas mostram que a maioria dos internautas costuma acessar apenas a primeira página de resultados em sites de busca e poucos rolam a barra de navegação, acessando os sites que aparecem nas primeiras 10 posições, negligenciando os demais sites. Estes sites negligenciados podem conter informações qualitativamente melhores do que os primeiros colocados que são rastreados por meta tags quantitativas (NIELSEN; LORANGER, 2006).

Com relação às secretarias e institutos ligados à agricultura, eles foram mais lembrados pelos técnicos de Cataguases (21\%). Os citados foram: Instituto Mineiro de Agropecuária - IMA, Instituto Estadual de Florestas - IEF, Central Estadual de Abastecimento de Minas Gerais - CeasaMG, Secretaria de Estado de Agricultura, Pecuária e Abastecimento - Seapa-MG, Instituto Brasileiro do Meio Ambiente e dos Recursos Naturais Renováveis- Ibama e Fundação Estadual do Meio Ambiente - Feam. Entre as outras instituições estão as empresas privadas de insumos, bancos e associações agropecuárias.

A atualização técnica está entre as principais razões para o acesso à Web na empresa de Ater. Esta motivação, portanto, está relacionada à obtenção de informações eletrônicas de natureza técnica. Por este motivo, os entrevistados foram questionados sobre a utilização de sites, exclusivamente para a atualização técnica profissional. As respostas podem ser verificadas resumidamente na Tabela 2.

Tabela 2 - Preferência por fontes e sites de informações utilizados para atualização técnica, por microrregião e geral

\begin{tabular}{l|rrr}
\hline Fontes e sites de informação & Uberaba (\%) & Cataguases (\%) & Geral (\%) \\
\hline Instituições públicas de pesquisa & 80 & 93 & 86 \\
Sites especializados em agropecuária & 27 & 29 & 28 \\
Universidades públicas & 27 & 0 & 14 \\
Outras fontes e sites & 7 & 7 & 7 \\
\hline Total & $\mathrm{RM}(*)$ & $\mathrm{RM}\left({ }^{*}\right)$ & $\mathrm{RM}\left({ }^{*}\right)$ \\
Base $\left(^{* *}\right)$ & 29 & 29 & 29 \\
\hline
\end{tabular}

Fonte: Dados da pesquisa. $\left({ }^{*}\right) \mathrm{RM}=$ Respostas múltiplas, com percentagens excedendo a $100 \%$

$(* *)$ Base $=$ número de respondentes. 
Na comparação com as microrregiões, somente houve diferença significativa com relação ao acesso aos sites destas universidades, pois as citações apresentadas são todas de técnicos de Uberaba. Em Cataguases as universidades não foram lembradas. O que chama atenção é a pouca utilização, em geral, de sites de universidades públicas, pois seria uma fonte de informação técnica importante e confiável. Isto pode ser explicado, em parte, pois a imagem da universidade ainda é atrelada ao desenvolvimento de pesquisa básica (não aplicadas em problemas cotidianos e mais complexos) e já a de instituições, como a Embrapa, ao da pesquisa aplicada e utilitária. Essa percepção pode gerar resistência no acesso as informações geradas pelos sites das Universidades.

Todas as universidades ${ }^{1}$ públicas citadas são da Região Sudeste do país. A preferência por estas universidades podem estar ligadas à familiaridade e à proximidade às microrregiões estudadas, e por serem referência nas áreas de ciências agrárias.

Com relação a estes sites de informação técnico-científica, a frequência média de visitação pela maior parte dos informantes é de até 3 vezes na semana (55\%). E a menor frequência é de até 3 vezes por mês (3\%). Considerando os dados separados por microrregião, a maior diferença notada foi com relação à frequência 1 vez por semana, 27\% em Uberaba e 7\% em Cataguases. O acesso diário só foi citado pelos técnicos de Uberaba (todos de cooperativas), bem como as frequências de 1 até 3 vezes ao mês somente em Cataguases. Em se tratando de técnicos de extensão rural, a média de três vezes por semana é razoável, considerando que o trabalho de campo, fora do escritório, é a principal atividade e que a maioria não tem acesso remoto. As outras médias se mantiveram mais uniformes (Tabela 3).

Tabela 3 - Frequência média de visitação em sites de informação técnicocientífica por microrregião

\begin{tabular}{l|rr|r}
\hline Tipo de site de Web & \multicolumn{2}{|c|}{ Região } & \multirow{2}{*}{ Total geral (\%) } \\
\hline Diariamente & Cataguases (\%) & Uberaba (\%) & \\
Até 3 vezes por semana & -- & 13 & 7 \\
1 vez por semana & 64 & 47 & 55 \\
Até 3 vezes por mês & 7 & 27 & 17 \\
1 vez por mês & 7 & -- & 3 \\
Raramente & 14 & -- & 7 \\
\hline Total & 7 & 13 & 10 \\
Base $\left(^{*}\right)$ & 100 & 100 & 100 \\
\hline
\end{tabular}

Fonte: Dados da pesquisa.

$(*)$ Base = número de respondentes

\footnotetext{
${ }^{1}$ As universidades citadas foram: Universidade de Lavras, Universidade Federal de Viçosa, Escola de Agricultura da Universidade de São Paulo e Universidade Federal Rural do Rio de Janeiro.
} 
Com a hipótese de que os mais velhos têm maior resistência a novas tecnologias, neste caso a Web, o quadro geral se mantém. A maior média continua sendo a de até 3 vezes na semana, para todas as faixas de idade, com destaque para os mais velhos (67\% - acima de 50 anos). Com relação aos mais jovens (31 a 40 anos) estão as duas maiores frequências (50\%). As três menores não tiveram indicação desta faixa etária.

Analisando os dados pela variável escolaridade, segue-se a mesma tendência identificada acima. A exceção veio do grupo da especialização, pois a frequência três vezes por semana empata com a de 1 vez na semana (37,5\% cada uma). No grupo dos graduados está tanto a maior (todo dia) quanto a menor frequência média (raramente) com 18\% cada uma, indicando que não há muita lógica, para o público estudado, com relação à assiduidade de acesso a sites de divulgação científica e o nível de escolaridade. Para aprofundar na preferência do público pesquisado, foram indagados sobre quais assuntos técnicos eles procuram nestes sites, para qual as principais respostas estão listadas na Tabela 4.

Tabela 4 - Assuntos técnicos acessados nos sites, por microrregião

\begin{tabular}{l|r|r|c}
\hline \multirow{2}{*}{ Tipo de assuntos técnicos } & \multicolumn{2}{|c|}{ Região } & \multirow{2}{*}{$\begin{array}{c}\text { Total geral } \\
(\%)\end{array}$} \\
\cline { 2 - 3 } & Cataguases (\%) & Uberaba (\%) & \\
\hline Nutrição animal & 64 & 60 & 62 \\
Qualidade do leite & 36 & 47 & 41 \\
Sanidade animal & 36 & 33 & 34 \\
Reprodução animal & 29 & 13 & 21 \\
Sistema produção de leite & 29 & 13 & 21 \\
Instalações & 14 & 20 & 17 \\
Mercado & 14 & 20 & 17 \\
Genética animal & 7 & 13 & 10 \\
Meio ambiente & -- & 13 & 7 \\
Outros assuntos $(*)$ & 36 & 33 & 34 \\
\hline Total & $\mathrm{RM}(* *)$ & $\mathrm{RM}(* *)$ & $\mathrm{RM}\left({ }^{* *}\right)$ \\
Base $(* * *)$ & 14 & 15 & 29 \\
\hline
\end{tabular}

Fonte: dados da pesquisa.

$\left({ }^{*}\right)$ Os outros assuntos são aqueles que receberam apenas uma indicação de preferência, dentre eles estão: aves, solos, cultivo e manejo de culturas diversas (mandioca, pupunha, frutas, milho, feijão, eucalipto, cana, silvicultura, café).

$\left({ }^{* *}\right) \mathrm{RM}=$ respostas múltiplas, com percentagens excedendo a $100 \%$

$(* * *)$ Base $=$ número de respondentes.

Os assuntos que despertam maior interesse dos técnicos são os relacionados à nutrição animal. Isto pode ser explicado pela relevância do tema e a demanda dos produtores de leite. Pela importância da alimentação para os animais e pelo alto valor dos insumos agrícolas desta 
categoria, o que reflete em maior custo e preço do leite aos produtores. Por isso, esse tema é bastante demandado pelos produtores e está em primeiro lugar na preocupação dos técnicos. Entre os assuntos específicos citados, está a divisão de pastagens em piquetes (50\%), adubação de pastagens (33\%) e manejo alimentar na época seca (cana+ureia, volumoso, concentrado) com $28 \%$.

A qualidade do leite pode ser vista em $41 \%$ dos respondentes. Assuntos como higiene de ordenha, células somáticas, normativa 51 e tanques comunitários foram os que apareceram como os de maior interesse por informações técnicas. Os assuntos sanidade (34\%) e reprodução animal (21\%), apesar de não aparecerem entre as prioridades dos técnicos, são de grande relevância para o trabalho extensionista. Os temas específicos demandados foram os mais voltados às doenças (mastites, tuberculose e brucelose) e biotécnicas aplicadas, tais como: inseminação artificial e transferência de embriões.

Dentre os sistemas de produção indicados, o de Integração Lavoura-Pecuária-Floresta (ILPF) aparece com $50 \%$ de apontamento pelos técnicos. Isso pode representar uma mudança significativa de paradigma, pois este sistema leva em conta alternativas sustentáveis de produção, como a rotação de atividades agrícolas, silvicultura e pastoreio. Esta preocupação reflete também na indicação pelos técnicos do tema meio ambiente, apesar de apenas $7 \%$ deles indicarem na pesquisa.

Os assuntos menos demandados ( $3 \%$ cada um), como era de se esperar, pela característica da amostra (composta por técnicos que trabalham prioritariamente com produtores de leite), foram os relacionados a outras culturas agrícolas e de produção animal. Em se tratando de instituições, os temas mais demandados pelas cooperativas são qualidade do leite (55\%) e reprodução animal (44\%). Na Emater-MG os temas preferidos são nutrição animal (65\%) e qualidade do leite (35\%). As análises acima podem ser mais bem explicadas quando verificada a finalidade de utilização das informações e assuntos priorizados pelos técnicos, o que pode ser conferido na Tabela 5.

No geral, os assuntos indicados estão entre os mais demandados por produtores de leite e os principais problemas técnicos da produção de leite no país, como alimentação, qualidade e sanidade. Analisando sob o enfoque das instituições, há uma inversão nas finalidades apresentadas acima. Enquanto os técnicos da instituição pública dizem que utilizam as informações com o propósito de atendimento da demanda técnica dos produtores rurais (70\%), aqueles das cooperativas utilizam mais para aperfeiçoamento técnico (75\%) 
Tabela 5 - Propósito de utilização da informação técnica acessada pela Web, por microrregião

\begin{tabular}{l|c|c|c}
\hline \multirow{2}{*}{ Descrição } & \multicolumn{2}{|c|}{ Região } & TOTAL \\
\cline { 2 - 3 } & $\begin{array}{c}\text { Cataguases } \\
(\%)\end{array}$ & $\begin{array}{c}\text { Uberaba } \\
(\%)\end{array}$ & $\begin{array}{c}\text { GERAL } \\
(\%)\end{array}$ \\
\hline Atendimento técnico aos produtores rurais & 60 & 53 & 56 \\
Aperfeiçoamento técnico profissional & 40 & 47 & 44 \\
\hline Total & 100 & 100 & 100 \\
Base $(*)$ & 14 & 15 & 29 \\
\hline
\end{tabular}

Fonte: dados da pesquisa.

$\left({ }^{*}\right)$ Base $=$ número de respondentes.

Isso demonstra uma tendência mais reativa dos técnicos de Ater pública e proativa dos técnicos das cooperativas, se antecipando aos temas demandados. A grande demanda por visitas ao campo e a maior abrangência e heterogeneidade dos produtores atendidos pela Emater-MG devem ser a causa dessa atitude aparentemente reativa. Os dados sobre a apropriação de informações técnicas por canais convencionais e via Web podem ser vistos na Figura 1.

Figura 1 - Utilização de canais convencionais e via Web para obtenção de informações técnicas

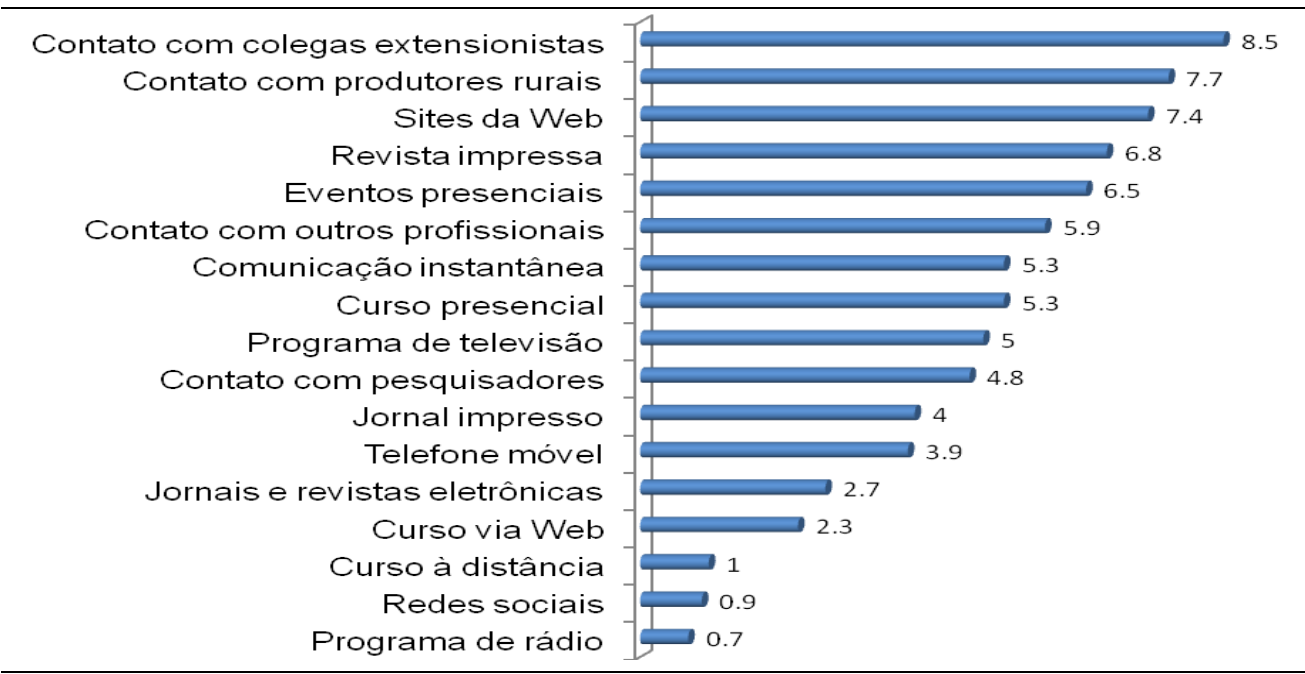

Fonte: Dados da pesquisa

$\left({ }^{*}\right)$ Os canais foram enumerados pelos respondentes em ordem decrescente de utilização

$(1,2,3,4,5)$ onde 1 é a menor utilização e 5 a maior e zero foi considerado a não-utilização.

No geral, os dados demonstram que os canais e instrumentos de comunicação mais convencionais ainda são os preferidos pelo público estudado, como a comunicação interpessoal, e os contatos (pessoais ou por telefone) com colegas e produtores rurais figuram nos dois primeiros lugares, o que pode ser explicado, pois são canais mais ricos e que possibilitam a interação mútua, feedback imediato e diminuem os ruídos na comunicação, como bem pontuado 
por Sousa et al. (2018). A facilidade de conversar sobre assuntos técnicos com colegas e produtores rurais, pela proximidade e disponibilidade, pode também ser um dos motivos da preferência e deve ser considerado.

Aos poucos os novos canais virtuais vão sendo incorporados como fontes de informação pelos extensionistas, como pode ser observado na indicação do site figurando entre os três primeiros colocados, e a comunicação instantânea (skype, messenger, chat etc.) entre os seis primeiros, na preferência de utilização dos extensionistas. No entanto ao considerar as cinco últimas preferências, encontram-se três veículos Web, as redes sociais, cursos, jornais e revistas eletrônicas (Ver Tabela 6).

Tabela 6 - Canais ou meios de comunicação utilizados, por microrregião

\begin{tabular}{|c|c|c|c|}
\hline \multirow[b]{2}{*}{ Canal / Instrumento } & \multicolumn{2}{|c|}{ Utilização } & \multirow{2}{*}{$\begin{array}{c}\text { Total gera } \\
(\%)\end{array}$} \\
\hline & $\begin{array}{c}\text { Cataguases } \\
(\%)\end{array}$ & $\begin{array}{c}\text { Uberaba } \\
(\%)\end{array}$ & \\
\hline Contato com colegas extensionistas & 100 & 100 & 100 \\
\hline Sites da Web & 100 & 100 & 100 \\
\hline Revista impressa & 100 & 100 & 100 \\
\hline Contato com produtores rurais & 100 & 93 & 97 \\
\hline Eventos presenciais & 86 & 100 & 93 \\
\hline Curso presencial & 86 & 100 & 93 \\
\hline Programa de televisão & 92 & 93 & 93 \\
\hline Contato com pesquisadores & 93 & 87 & 90 \\
\hline Contato com outros profissionais & 71 & 100 & 86 \\
\hline Jornal impresso & 71 & 80 & 76 \\
\hline Comunicação instantânea & 50 & 73 & 76 \\
\hline Telefone móvel & 86 & 33 & 59 \\
\hline Jornal e revista eletrônicos & 50 & 67 & 59 \\
\hline Curso via Web & 29 & 67 & 48 \\
\hline Curso à distância & 29 & 27 & 28 \\
\hline Redes sociais & 14 & 33 & 24 \\
\hline Programa de radio & 29 & 20 & 24 \\
\hline Total & $\mathrm{RM}(*)$ & $\mathrm{RM}\left({ }^{*}\right)$ & $\mathrm{RM}\left({ }^{*}\right)$ \\
\hline Base $(* *)$ & 14 & 15 & 29 \\
\hline
\end{tabular}

Fonte: Dados da pesquisa.

$\left.{ }^{*}{ }^{*}\right) \mathrm{RM}=$ respostas múltiplas, com percentagens excedendo a $100 \%$

$(* *)$ Base $=$ número de respondentes

Apesar de os contatos com pesquisadores não estarem entre os preferidos dos extensionistas, este instrumento é muito importante para obtenção de informação técnica de qualidade, pois são aqueles profissionais que estariam, em princípio, em contato direto com as pesquisas científicas e podem tirar dúvidas e apontar direcionamentos técnicos mais confiáveis 
para estes extensionistas. Dentre os pesquisadores com maior menção pelos técnicos estão os da Embrapa Gado de Leite (52\%) e da Epamig (45\%).

Em comparação com as microrregiões (Tabela 6), destaca-se a utilização mais significativa dos novos veículos virtuais (comunicação instantânea e cursos via Web, redes sociais, jornais e revistas eletrônicos) pelos técnicos de Uberaba. Com relação a Cataguases, o que pode ser destacado é a utilização do celular (85\%).

A grande utilização de veículos de massa para obtenção de informações técnicas, como os programas de televisão (93\%), é outro ponto a ser destacado. Dentre os programas citados pelos técnicos estão os mais antigos e conhecidos, tais como: Globo Rural (48\%), Canal Rural (20\%) e Minas Rural, da Emater (16\%). Em contrapartida, os programas de rádio não são as fontes e canais principais para a obtenção de informações técnicas. Eles são vistos mais como meios eficientes para os produtores rurais. Dentre as revistas impressas lembradas pelos entrevistados estão as mais especializadas, tais como: Informe Agropecuário da Epamig (52\%) e a Balde Branco da Cooperativa Central de Laticínios do Estado de São Paulo (45\%).

Com relação à preferência dos entrevistados por veículos convencionais e virtuais nas faixas etárias, o panorama é o seguinte: $85 \%$ dos mais jovens (até 40 anos) acessam jornais e revistas eletrônicas, $67 \%$ utilizam comunicação instantânea, 57\% fizeram cursos Web e apenas $27 \%$ utilizam rede social. Entre os mais velhos, a situação é um pouco diferente, ou seja, $38,5 \%$ responderam que acessam jornais e revistas eletrônicas, 53\% utilizam comunicação instantânea, $40 \%$ fazem cursos Web e 19,5\% disseram que utilizam redes sociais. Esta posição na faixa etária de maior idade é conflitante com que foi relatado por eles anteriormente quanto ao sentimento negativo com relação à Web.

No que se refere à escolaridade, pode-se afirmar que a menor incidência de utilização de comunicação instantânea está na graduação (45\%) e a maior no ensino médio (77\%). Entre especialistas e mestres o percentual é de $67 \%$. A metade dos especialistas utiliza cursos Web, sendo $45 \%$ são da graduação e $33 \%$ do ensino médio. Dentre os que menos utilizam estão os do ensino médio para cursos Web, com 67\%, e os do grupo de especialistas (75\%) têm idade superior a 40 anos. Para a comunicação instantânea, dos formados no ensino médio, a totalidade é composta pelos mais velhos (acima de 40 anos)

A utilização e a percepção de importância dos canais de comunicação de informações não podem ser vistas como a mesma coisa. Na primeira, há influências de diversos fatores, como demanda interna ou institucional, demanda externa de vários atores, recursos financeiros, dentre outros. Já a percepção de importância está ligada a que os atores consideram, dentre as 
alternativas, aquele canal que atenda ao que está sendo proposto de maneira mais eficiente e eficaz, muitas vezes não levando em consideração os recursos demandados. Ou até mesmo os que eles têm mais familiaridade.

Para tal, foi sugerido aos informantes que dentre os canais apresentados no tópico anterior, apontassem aqueles que consideram os mais importantes na obtenção de informações técnicas ou mesmo indicassem outros canais. A Figura 2 retrata essas preferências. Os dados demonstram que, para os técnicos extensionistas, o contato com os pesquisadores é a forma mais importante. Novamente uma comunicação interpessoal figura no primeiro lugar. Esta importância pode estar em parte ligada a percepção de autoridade (técnica) da fonte, refletindo em credibilidade e confiança no canal escolhido. A possibilidade de feedback imediato também pode ter sido levada em conta na escolha do canal.

Em segundo lugar está um veículo virtual. Para a escolha deste último, critérios como rapidez e quantidade de conteúdo devem ter sido reparados pelos técnicos. E mais uma vez o contato com colegas da mesma área está entre os primeiros lugares. A confiança e proximidade são critérios importantes para a percepção de importância.

Figura 2 - Canais de comunicação mais importantes para obtenção de informações técnicas

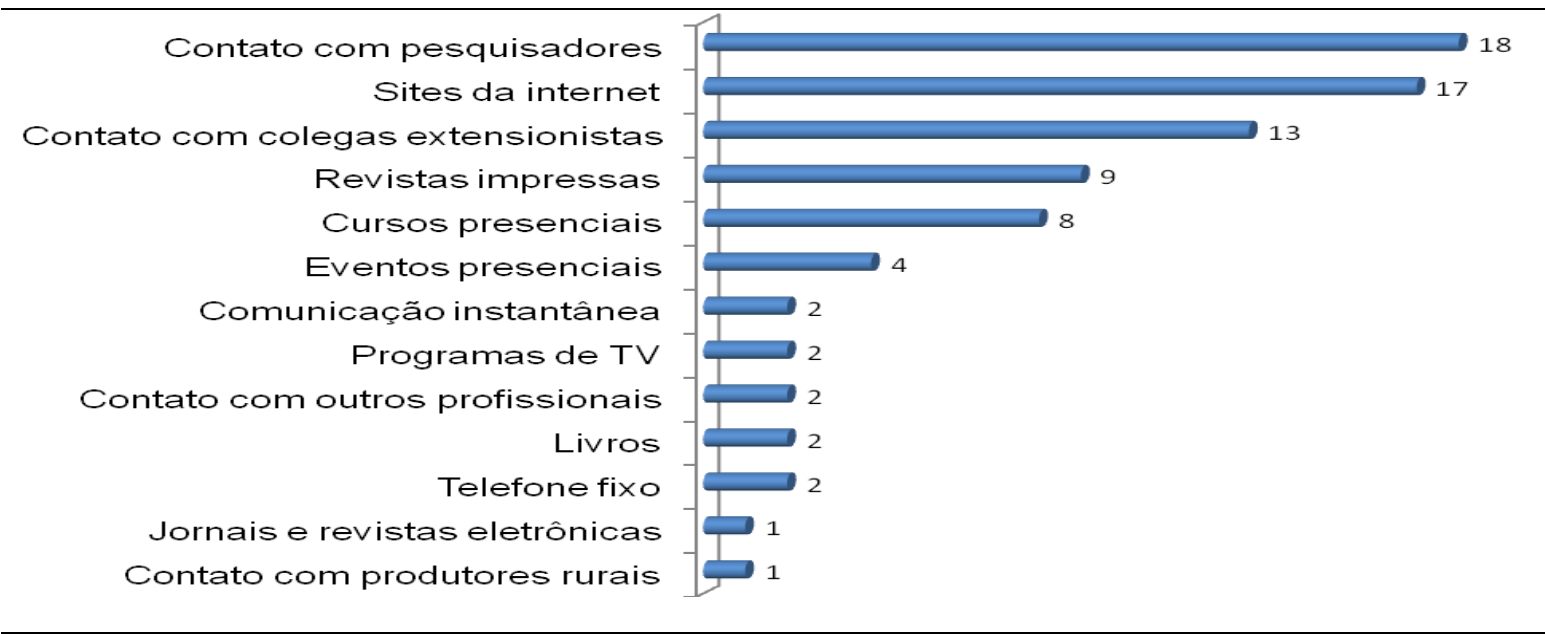

Fonte: Dados da pesquisa.

Os novos veículos interativos trazidos pela Web não são vistos como os mais importantes para obter informações técnicas, pela maioria dos entrevistados. Não houve lembrança das redes sociais e cursos Web. Apenas a comunicação instantânea foi lembrada por dois entrevistados. A apropriação e percepção destes canais como fonte de informação pela comunicação interativa ainda não é percebida pelos técnicos. A frequência média de acesso a algumas fontes de informações sobre pesquisa e extensão, públicas e privadas, está apresentada na Tabela 7. 
Tabela 7 - Frequência de acesso a fontes e canais de informação técnica

\begin{tabular}{|c|c|c|c|c|c|c|c|}
\hline Fonte/Canal & $\begin{array}{l}\text { Diária } \\
(\%)\end{array}$ & $\begin{array}{l}\text { Semanal } \\
(\%)\end{array}$ & $\begin{array}{c}\text { Mensal } \\
(\%)\end{array}$ & $\begin{array}{l}\text { Às vezes } \\
(\%)\end{array}$ & $\begin{array}{c}\text { Difícil } \\
(\%)\end{array}$ & $\begin{array}{c}\text { Total } \\
\%\end{array}$ & $\begin{array}{c}\text { Total/base } \\
(*)\end{array}$ \\
\hline $\begin{array}{l}\text { Publicação impressa de } \\
\text { instituição de pesquisa }\end{array}$ & 7 & 59 & 31 & 3 & -- & 100 & 29 \\
\hline $\begin{array}{l}\text { Publicação impressa de } \\
\text { instituição de extensão }\end{array}$ & 10 & 55 & 24 & 7 & 3 & 100 & 29 \\
\hline $\begin{array}{l}\text { Publicação impressa de } \\
\text { empresas privadas }\end{array}$ & 7 & 28 & 41 & 14 & 10 & 100 & 29 \\
\hline $\begin{array}{l}\text { Site e blog de instituição de } \\
\text { pesquisa }\end{array}$ & 10 & 59 & 21 & -- & 10 & 100 & 29 \\
\hline $\begin{array}{l}\text { Site e blog de instituição de } \\
\text { extensão }\end{array}$ & 24 & 24 & 21 & 21 & 10 & 100 & 29 \\
\hline $\begin{array}{l}\text { Site e blog de instituição de } \\
\text { empresas privadas }\end{array}$ & 10 & 21 & 14 & 31 & 24 & 100 & 29 \\
\hline Site de universidades & -- & 34 & 21 & 21 & 24 & 100 & 29 \\
\hline
\end{tabular}

Fonte: Dados da pesquisa. (*) RM = respostas múltiplas, com percentagens excedendo a $100 \%$.

$(* *)$ Base $=$ número de respondentes

Para os técnicos entrevistados, os sites são canais importantes de informação e não se pode desconsiderar que a Web na apreciação deles (83\%) é uma fonte primordial de informações de natureza técnica para o serviço de Ater e por isso deve ser bem trabalhada para atender os anseios desse público. Assim, como esses mediadores do meio rural, os agricultores também têm receio na utilização da Internet para ser utilizada com a finalidade de buscar informações técnicas para a propriedade, apontou o estudo de Conceição (2016).

\section{Considerações finais}

Desde sua criação e introdução no Brasil, na década de 1990, a Web vem despertando interesse como meio de comunicação, de informação e de interatividade entre pessoas, instituições e profissionais de diversas áreas, incluindo a extensão rural. Alguns estudos mostrados anteriormente colocam esta ferramenta tecnológica como meio importante e bastante utilizado por extensionistas rurais para obtenção de informações técnicas, em comparação a outros veículos e fontes convencionais. Porém apontam também para algumas limitações com relação aos novos veículos e a tecnologia Web.

Neste sentido, este estudo buscou entender a apropriação da Web pelos extensionistas das microrregiões de Uberaba e Cataguases, como canal de informação e, também, comunicação (interação) na sua prática profissional junto aos atores envolvidos com a pesquisa agropecuária.

A análise dos dados aponta para o fato de que, nas regiões estudadas, o serviço de Ater ainda é predominantemente masculino e as áreas de formação e especialização são 
principalmente agrárias (veterinária e agronomia). A área ambiental junto com a de veterinária aparece como formação complementar preferida pelos técnicos de Cataguases.

$\mathrm{Na}$ comparação com as microrregiões, Uberaba possui os técnicos mais jovens, com menor tempo de serviço na empresa e os mais especializados. Os serviços de conexão e acesso à Internet também são privilegiados, refletindo em técnicos mais satisfeitos com a infraestrutura disponibilizada pela instituição e que navegam mais tempo na Web. Com relação aos técnicos de Cataguases predomina a faixa de idade superior a 40 anos, estes possuem mais tempo de serviço na empresa e têm infraestrutura de conexão menos privilegiada nos municípios que trabalham, refletindo em técnicos menos satisfeitos com o acesso à Web e com metade do tempo de navegação com relação a Uberaba. Ademais as variáveis idade e escolaridade possuem correlação ao acesso e uso da Internet e Web para o público pesquisado.

De maneira geral, os meios de comunicação mais convencionais e interpessoais são os preferidos pelo público estudado para obter informações de pesquisa, como os contatos com colegas extensionistas e produtores rurais por serem canais mais ricos e possibilitarem interação mútua (dialógica), feedback imediato e diminuição dos ruídos na comunicação. Outros canais de grande utilização são as revistas especializadas impressas e os programas de televisão como fontes de informação técnica. Aos poucos os novos canais virtuais vão sendo apropriados como fontes de informação pelos extensionistas, como os sites, em segundo lugar na preferência. A comunicação instantânea também está sendo bastante utilizada pelos técnicos, muito incentivada pela instituição a fim de minimizar recursos com telefonia.

Apesar de serem muito importantes para obtenção de informação técnica de qualidade, os contatos com pesquisadores não estão entre os mais utilizados pelos extensionistas. Esta distância é negativa do ponto de vista dos técnicos, pois são aqueles profissionais que estão em contato direto com as pesquisas científicas e podem tirar dúvidas e apontar direcionamentos técnicos mais confiáveis. Porém estes contatos estão se tornando cada vez mais raros. E muitos relataram não saber quem são estes pesquisadores e nem com o que eles trabalham, o que é negativo para a retroalimentação dos temas de pesquisa ligados aos problemas práticos da atividade leiteira.

Com relação ao acesso a informações digitais, a pesquisa mostrou que os técnicos têm o hábito de acessar informações pela Web e que preferem os conteúdos técnicos e de mercado agropecuário. As razões principais desse acesso são o atendimento e orientação aos produtores e o aperfeiçoamento profissional. 
Sendo assim a Web, no que se refere aos recursos estáticos e de informação, está sendo apropriada pelos técnicos de Ater e o site é visto como o principal e mais importante meio de comunicação neste sentido. As fontes virtuais principais são os sites de instituições públicas de pesquisa, como a Embrapa e a Epamig. Os sites das universidades não estão na preferência dos técnicos, por serem vistos como repositórios de informações com foco em pesquisas básicas (mais complexas) não aplicadas e, também, de ensino. Os temas mais acessados são os relacionados aos principais problemas demandados pelos produtores atendidos, como nutrição de animais e qualidade do leite.

\section{Referências}

BARBOSA, A. C. L. S. Leitura e escrita na Web. Linguagem em (Dis)curso - LemD, Tubarão, v.5, n.1, p. 153-183, 2004.

BIDARRA, J. Aproximação a uma metodologia de concepção de videogramas para o ensino a distância. Lisboa: Universidade Aberta, 1994.

BLUMER, H. Symbolic interactionism: Perspective and method. Englewood Cliffs, NJ: PrenticeHall, 1969.

CASTELLS, M. A galáxia internet: reflexões sobre a internet, os negócios e a sociedade. Rio de Janeiro: Jorge Zahar, 2003.

CONCEIÇÃO, A. F. Internet pra quê? - a construção de capacidades e as TIC no processo de desenvolvimento rural. 2016. Tese (Doutorado em Desenvolvimento Rural) - Curso de Pósgraduação em Desenvolvimento Rural, Faculdade de Ciências Econômicas, Universidade Federal do Rio Grande do Sul, Porto Alegre, 2016.

ESTEVÃO, P; PINHO, J. B; SOUSA, D. N. A Web como fonte de informação científica e de interação entre pesquisa e extensão rural. In: Cleiton Silva Ferreira Milagres; Diego Neves de Sousa. (Org.). Cooperativismo, Extensão Rural e Processos Participativos. Palmas: EDUFT, 2016 , v. 1, p. $191-244$

LANDOW, G. P.; DELANY, P. Hypertext, Hypermedia and Literary Studies: the State of the Art. In: DELANY, P.; LAKOFF, G. (Org.). Hypermedia and Literary Studies. Cambridge: The MIT Press, 1991.

LEMOS, A. Cibercultura: tecnologia e vida social na cultura contemporânea. 2. ed. Porto Alegre: Sulina, 2004. 295 p.

LÉVY, P. Cibercultura. São Paulo: Editora 34, 1999. 260 p.

LÉVY, P. O que é o virtual? São Paulo: Editora 34, 1997. 157 p.

LIMA, I. A. A extensão rural e a produção do conhecimento: a fundamentação científica dos planos municipais de desenvolvimento rural do Programa Nacional de Fortalecimento da Agricultura Familiar (Pronaf) no Estado de São Paulo. 2001. 129 f. Tese (Mestrado) Universidade Estadual de Campinas, Campinas, SP. 
MAÇADA, D. L.; TIJIBOY, A. V. Aprendizagem cooperativa em ambientes telemáticos. In: CONGRESSO DA REDE IBEROAMERICANA DE INFORMÁTICA EDUCATIVA - RIBIE, 4., 1998, Brasilia, DF. Anais... Brasília, 1998.

NIELSEN, J.; LORANGER, H. Projetando Websites com usabilidade. Rio de janeiro: Campus, 2006. PONTE, J. P. Tecnologias de informação e comunicação na formação de professores: que desafios? Revista Ibero-Americana de Educação, n. 24, p. 63-90, set./dez. 2000.

PRIMO, A. F. T. O aspecto relacional das interações na Web 2.0. In: CONGRESSO BRASILEIRO DE CIÊNCIAS DA COMUNICAÇÃO, 29., 2006, Brasília, DF. Anais... Brasília: Intercom; UnB, 2006. Acesso em: set. 2010.

PRIMO, A. F. T. Enfoques e desfoques no estudo da interação mediada por computador. Universidade Federal do Rio Grande do Sul, [2005]. Disponível em:

<http://www6.ufrgs.br/limc/PDFs/enfoques_desfoques.pdf>. Acesso em: set. 2010.

PRIMO, A. F. T. Interação mútua e reativa: uma proposta de estudo. In:

CONGRESSO BRASILEIRO DE CIÊNCIAS DA COMUNICAÇÃO, 21., 1998, Recife. Anais... Recife: Intercom, 1998.

RADFAHRER, L. Design/Web/design:2. São Paulo: Market Press, 2001. 218 p.

RAFAELI, S. Interactivity: From new media to communication. In: SAGE Annual Review of Communication Research: advancing communication science. Beverly Hills: Sage, 1988. v. 16, p. 110-134.

RODRIGUES, B. Webwriting - Redação \& Informação para a Web. Rio de Janeiro: Brasport, 2016.

SANTOS, D. T. dos. Humildade para aprender: sinônimo de inteligência. Como enfrentar os desafios da educação continuada, exigidos de jornalistas, cientistas, tecnólogos e outros divulgadores de C \& T. Revista de Ciência e Comunicação, v. 2, n. 2, jul. 2005.

SILVA, L. Globalização das redes de comunicação: uma reflexão sobre as implicações cognitivas e sociais. In: ALVES, J. A.; CAMPOS, P.; BRITO, P. Q. (Ed.). O futuro da internet. Matosinhos: Centro Atlântico, 1999. p. 53-63.

SIMON, I. Nascimento da Teia Mundial. In: MANDEL, A.; SIMON, I.; DeLYRA, J. L. Informação: computação e comunicação. IME/USP, São Paulo, 1997.

SOUSA, D. N; MACEDO, A. S; MILAGRES, C. S. F; COSTA, M. S; MOURA, R. A. A comunicação na gestão de cooperativas. Cadernos de Comunicação (UFSM), v. 22, p. 84-103, 2018.

TERRA, C. F. Comunicação corporativa digital: o futuro das relações públicas na rede. 2006. 173 f. Dissertação (Mestrado) - ECA/USP, São Paulo, SP.

TRIVINHO, E. Epistemologia em ruínas: a implosão da Teoria da Comunicação na experiência do cyberspace. Revista FAMECOS, Porto Alegre, n.5, p. 73-81, 1996. 